\title{
From Early Curiosity to Space Wide Web: Emergence of the Small Satellite Innovation Ecosystem
}

\section{Yue Song, Auburn University; Devi Gnyawali, Virginia Tech; Lihong Qian, Portland State University}

Research Questions:
How did the small satellite
ecosystem emerge and
evolve?
Although the first modern
small satellite UoSat-1 was
successfully launched in 1981 ,
and the CubeSat dominant
design was introduced in
1999, the sales takeoff of
small satellites did not occur
until the early 2010s. What
explains this long time
period?

Research Questions:

How did the small satellite evolve?

\section{Research Background: Innovation Ecosystem}

Literature on innovation ecosystem has identified a few necessary conditions for a seed innovation to become an innovation ecosystem:

$\square \quad$ Multilateral interdependency: the value creation for one firm depends on value creation from other firms

$\square \quad$ Non-generic investments: firms make nonfungible investments into the specific technology

- Customer-centric, economic value proposition: mass market, economic benefits
Number of Small Satellites Launched by Year and Key Events in the Modern Small Satellite History

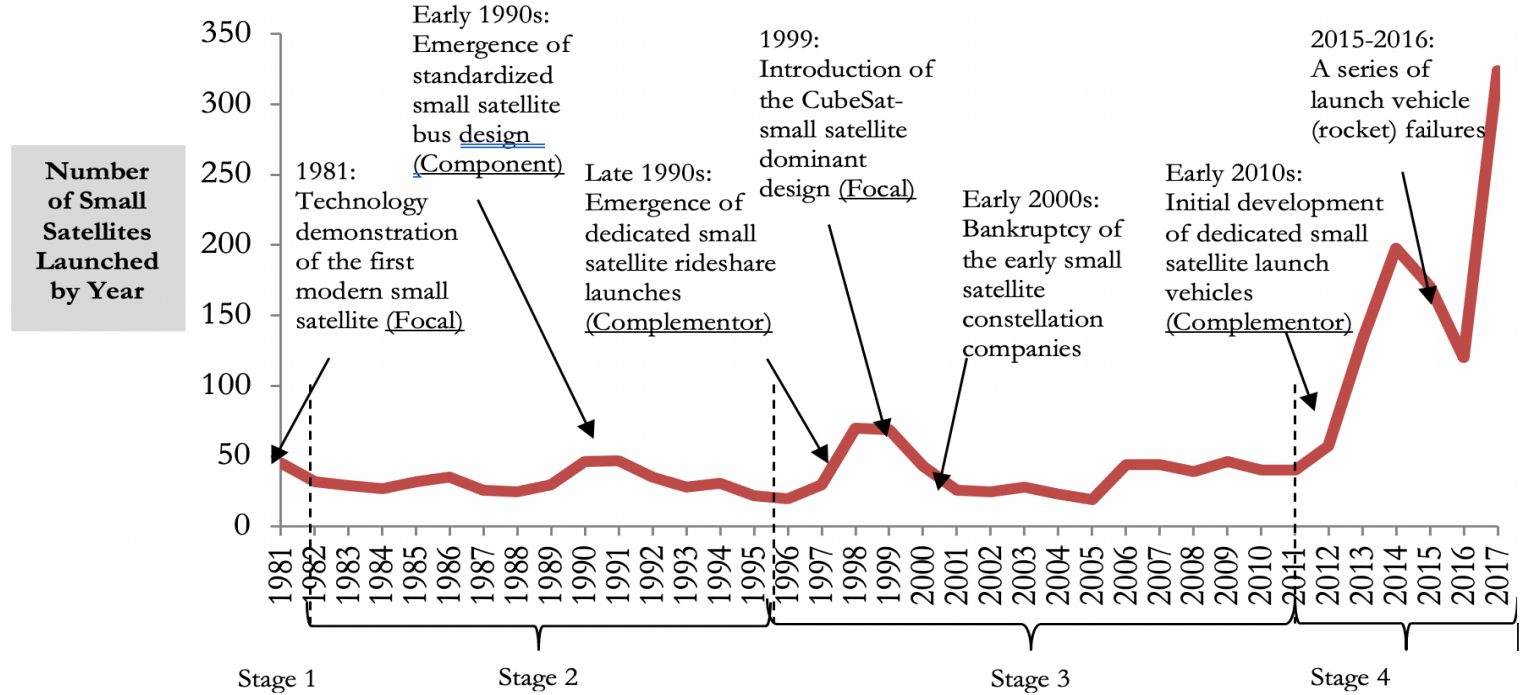

\section{Key Findings:}

It took the small satellite more than 30 years to evolve from a seed innovation to a complete innovation ecosystem

- Our analysis reveals a long-time struggle to develop and materialize an economic value proposition, absence of which stalled the development of the small satellite ecosystem.

$\square \quad$ Four stages of ecosystem evolution:

a $\quad 1981$ Technology demonstration. Only few firms making nonfungible investments into the technology

a 1982 early 1990s Technology reliability and non-commercial usefulness of the technology. Specialized components and buses start to emerge

a Late $1990 \sim$ ate 2000s Commercial usefulness of small satellites. Initial non-generic investments from launch vehicle providers

- Early 2010s now - Strong economic returns and establishment of the innovation ecosystem

The incremental investments from a collective of actors contributed to the ecosystem formation 